\title{
DENTAL IMPLANTS: BIOMATERIAL, BIOMECHANICAL AND BIOLOGICAL CONSIDERATIONS
}

Z.M. Isa, J.A. Hobkirk. Dental implants: Biomaterial, biomechanical and biological considerations. Annal Dent Univ Malaya 2000; 7: 27-35.

\section{ABSTRACT}

Currently many dental implant systems with varied and numerous components are available commercially, and with new implant systems and designs emerging, it is essential that the user understands that any system selected should be based on sound scientific principles and capable of osseointegration. This has been defined in many different ways, with biomaterial, biological and biomechanical factors being the main considerations. The final restoration is based on both biological tissue and mechanical components. As the success of osseointegration is based on the clinical outcome, clinicians must ensure that the stresses that the superstructure, implant, and surrounding bone are subjected to are within the tolerable limits of the various components, even though the degree of tolerance has not yet been fully defined.

Key words: dental implant, biomechanical, biomaterial, review.

\section{INTRODUCTION}

Dentists and scientists have for a long time been researching materials and techniques for providing predictable, efficient and effective methods of restoring a depleted dentition. Amongst the most versatile of these are osseointegrated implants. Dental implant therapy has realised significant progress in the last thirty years. Since the first scientifically documented clinical successess of Brånemark and his co-workers in the edentulous milieu (1), application of dental osseointegrated implants have progressed to be used in the partially dentate $(2,3)$, prosthetic rehabilitation of oral and maxillo-facial defects (4), and reconstruction of congenital defects in children and adolescents (5). One-step surgical implant techniques are currently being used $(6,7)$, besides the original Brånemark protocol of two-stage surgery for implant placement. Preliminary reports have also shown that placement of implants in irradiated jaws may give good results even wihout adjunctive hyperbaric oxygen therapy to provide support in areas with compromised blood flow after irradiation $(8,9,10,11)$. Osseointegration is also used in orthopaedic reconstruction of various parts of the human body (12).

Osseointegration was first described as a relationship where "bone tissue is in direct contact with the implant, without any intermediate connective tissue". It was later defined as a "direct structural and

\section{Review Article}

Z.M. Isa ${ }^{1}$ and J.A. Hobkirk ${ }^{2}$
'Department of Prosthetic Dentistry
Faculty of Dentistry, University of Malaya
50603 Kuala Lumpur, Malaysia
${ }^{2}$ Department of Prosthetic Dentistry
Eastman Dental Institute for Oral Health Care
Sciences, University College London (UCL)
University of London
Corresponding author - Z.M. Isa

functional connection between ordered and living bone and the surface of a load carrying implant" (13). These definitions were based on retrospective radiographic and light microscopic observations, and implied that direct bone contact occurs around the entire implant. However, with current techniques of ultrastructural investigation, this interpretation appears to have been overestimated, as $100 \%$ bone apposition is not necessarily obtained at the surface of the endosseous implant. Albrektsson and Johansson (14) indicated that the proportion of direct bone-to-implant contact varies with the material and design of the implant, as well as the state of the host bed, the surgical technique, and the time and conditions of loading. There is also varied morphology of bone apposing the implant, showing that osseointegration is a healing response consistent with the dynamic environment into which the prosthesis is inserted (15). Therefore, osseointegration is best defined as a "process whereby clinically asymptomatic rigid fixation of alloplastic materials is achieved, and maintained, in bone during functional loading" (16). Later, in 1994, Skalak and Brånemark (17) proposed that osseointegration be considered as the sum total of the following definitions, obtained from the clinical, biological, biomechanical, and microscopical points of view:

a. a fixture is osseointegrated if there are no signs and symptoms under functional load.

b. at the light microscopic level, osseointegration is seen as a direct structural and functional connection of new bone to the fixture without the interposition of connective or fibrous tissue, and that this connection is capable of carrying normal physiological loads.

c. there should be no progressive movement between the fixture and surrounding bone under functional loading. 
d. at the electron microscopic level, structures found within nanometres of most of the surface of the fixture should be identifiable as mineralised normal bone.

These definitions describe the end result of osseointegration, and while they are appropriate, the process of osseointegration itself is a lifelong activity of bone formation, adaptation to function and repair at the bone-implant interface. Cooper (18) pointed out that there is therefore, still a need, to define the cellular and molecular events controlling bone formation and maintenance at this site so that the process of osseointegration is predictable, especially in areas where bone is deficient.

\section{Criteria for the success of osseointegration}

Osseointegration is a highly successful clinical protocol, although this is influenced by many factors. These include the implant system and the status of the bone at the implant site $(19,20)$. Esposito et al. (21) provided a comprehensive review of the many parameters which have been developed and used over the years to evaluate the success and failure of osseointegrated implants. Zarb and Albrektsson (22) proposed that the following set of criteria be used to assess the outcome of implant supported prostheses. It highlights the essential clinical features of the successful osseointegration of implants, and includes:

a. the lack or absence of signs of infection (either early on in the healing period, or later during function) attributable to the implants,

b. no pain, discomfort, or sensitivity around the implants,

c. no observable mobility (which is always a clear sign of failure) when tested clinically, and

d. the mean vertical bone loss is less than $0.2 \mathrm{~mm}$ annually following the first year of function, compared to baseline measurements made after abutment connection.

Wide-ranging and extensive data to support the success of osseointegrated implants is available for the Brånemark implant system $(19,23,24)$. Other implant systems are relatively new, and adequate data is needed to form the basis for reliable statistics for a 10 -year follow-up period to meet the minimum success criteria proposed by Albrektsson et al. in 1986 (19).

Esposito et al. (25) reviewed in detail the factors that can lead to implant failure. The reasons for the loss of implants after osseointegration has occurred may be multifactorial, with prosthetic factors (usually due to overload) and bacterial infection as the major causes. However, the reasons for the implant's failure to osseointegrate are still unknown. Experimentally, excessive interfacial micromotion, rather than early loading per se, is acknowledged as one detrimental factor (26).

\section{Factors which determine the success of osseointegration}

Albrektsson et al. (19) first referred to the six important factors which determine the success of osseointegration. These are: implant biocompatibility, design characteristics, implant surface characteristics, state of the host bed, surgical technique, and implant loading conditions. LeGeros and Craig (27) categorised these factors into biomaterial, biomechanical and biologic determinants. In addition, patient motivation and oral hygiene procedures are also important considerations $(28,29)$. These factors are interdependent and interrelated, and their recognition has led to the long-term success associated with osseointegrated implants.

\section{Biomaterial factors}

Dental implants are used in the oral cavity to improve the stability of a prosthesis. In order to be successful clinically, implant materials must satisfy two essential requirements:

a. they must not be toxic to the cells in the surrounding tissues, or undergo dissolution and cause systemic damage to the patient;

b. they must be able to form a stable bone-implant interface that is capable of carrying occlusal loads, and transferring or distributing stresses to the adjacent bone so that bone vitality is maintained over long periods (30).

Three basic types of synthetic materials have been used for fabricating endosseous dental implants. These are metals and metal alloys, ceramics and carbons, and polymers. Metals and metal alloys used for clinical and experimental implants have included titanium and titanium alloys, tantalum, stainless steel, cobaltchromium alloys, gold alloys and zirconium alloys among others (31). These materials are selected based on their high corrosion resistance, strength, rigidity, ease of shaping and machining, and suitability for a wide range of sterilisation techniques. Although the mechanisms that lead to osseointegration with titanium implants are not fully known, metals in general do not form an interfacial bond with bone. The implant is typically connected to bone via a micro-mechanical interlock using a variety of surface designs and textures that are used to promote bony in-growth and improve the interfacial attachment (32).

Ceramics are generally hard materials with high compressive strengths. Carbon based materials are similar to ceramics, and due to their brittleness and low impact strengths, are not suitable for use in their bulk form in load-bearing applications. The choice of ceramics as implant materials is primarily due to efforts to develop materials based on crystalline structures which are bone-like and have similar physical properties to bone. Bioceramics may form two types of interfacial bond with bone: a bioactive ceramic is partially soluble, and forms bone via chemical reactions at the interface, while bioresorbable or biodegradable ceramics have a 
higher solubility, degrade gradually, and with time are replaced with bone $(27,30)$.

Different chemical compositions of calcium phosphate ceramics based on specific ratios of calcium and phosphorus are used clinically, both as a dense sintered material in non load-bearing areas, and as a plasma-sprayed coating for titanium implants $(33,34)$. These hydroxyapatite (HA) coatings may contribute to more rapid osseointegration and greater amounts of bone-implant contact than is associated with uncoated titanium in the early stages of healing. However, HA coated implants are not seen as superior to titanium devices in the long-term because the difference does not appear to be clinically significant after 12 months of implantation (35). In fact, bone contact with titanium may be more favourable in the long-term (36). This is attributed to interfacial problems related to the dissolution and weakening of the HA coatings, which have a tendency to become loose or dissociated from the central titanium implant (37).

In comparison to metals and ceramics, polymers are weak, and generally flexible. They may however, be synthesised in a variety of compositions and fabricated into many complex shapes and structures. They are mainly used as additives to give a beneficial secondary purpose, for example, as structural isolation for shockabsorption in load-bearing metallic implants (38).

Two forms of titanium ( $\mathrm{Ti}$ ) are principally used for endosseous dental implants. They are commercially pure titanium (cpTi, at least $99.5 \%$ pure $\mathrm{Ti}$ ) and a titanium alloy, titanium-aluminium-vanadium (Ti-6Al-4V). CpTi is available in four grades which vary in their oxygen content. Oxygen functions as a controlled strengthener in cpTi. As oxygen content increases, the strength of the metal increases and its ductility decreases (39). Nitrogen, carbon, hydrogen and iron are also present, but vary little between grades. Grade I cpTi is the purest and therefore the softest. Grade $4 \mathrm{cpTi}$ has the most oxygen at $0.4 \%$ by weight, and is the material used for dental implants.

Ti-6Al-4V also contains low concentrations of nitrogen, carbon, hydrogen, iron and oxygen, but additionally approximately 6 per cent by weight aluminium and 4 per cent by weight vanadium. Besides reducing the melting and casting temperatures, alloying other metals with $\mathrm{Ti}$ also increases the strength of the alloy and decreases its density (40). A stronger boneimplant interface may be achieved with $\mathrm{cpTi}$ than with Ti-6Al-4V, as greater removal torque forces were needed to loosen the interfacial connection between cpTi implants and the surrounding bone (41). This may indicate that $\mathrm{cpTi}$ is more favourable to bone cell differentiation than Ti-6Al-4V (42). The impaired bone formation with the Ti alloy may be related to the release of aluminium ions, which can be detrimental to bone cell differentiation $(14,43,44)$.

$\mathrm{Ti}$ is the 'material of choice' in implant dentistry (45). Its excellent corrosion resistance is due to the surface which oxidises spontaneously upon contact with air or tissue fluids. This layer, normally approximately $2-5 \mathrm{~nm}$ thick is primarily $\mathrm{TiO}_{2}$, but may contain $\mathrm{TiO}$ and $\mathrm{Ti}_{2} \mathrm{O}_{3}$ depending, partly on its method of preparation $(46,47)$. However, the oxide layer is not uniform or constant. The type and thickness of the oxide layer also depend upon other factors such as roughness of the surface, and treatments to passivate or sterilise the surface $(48,49,50,51,52)$. The oxide layer may undergo dissolution and allow a finite rate of diffusion of the oxide in the body $(53,54,55)$. However, there is little evidence that this has any clinical significance, and no case of local or systemic reaction to Ti has been reported (56).

As with all materials implanted in living tissues, Ti is not entirely inert and will elicit a response from the host tissue. Williams (57) described a biocompatible material as one "which possesses the ability to perform with an appropriate host response in a specific application", and consequently, Stanford and Keller (58) proposed that the term "osseointegration" reflects the results of a lack of a negative tissue response to $\mathrm{Ti}$, rather than the presence of an advantageous one. This is because Ti does not stimulate or induce mineralised tissue formation at the bone-implant interface. Rahal et al. (59) showed that $\mathrm{Ti}$ does not have the ability to induce osteogenesis from potential osteogenic precursor cells in mice marrow. Various studies have also shown that bone healing around machined Ti implants takes place by a gradual mineralisation process directed towards, but does not start, at the implant surface $(52,60,61)$.

A bioactive implant (i.e. an implant which bonds to bone) forms a hydroxycarbonate-apatite (HCA) layer on its surface when implanted (30). Ti is a reactive material, and Hanawa (62) found that it naturally forms calcium phosphate on its oxide layer in a neutral electrolyte solution simulating body fluids. The ratio of calcium and phosphate $(\mathrm{Ca} / \mathrm{P})$ in the $\mathrm{Ca}-\mathrm{P}$ layer formed was 1.63 , which is close to that of hydroxyapatite (1.67). He suggested that this layer may therefore present itself as a suitable surface for osseointegration. However, this Ca-P layer was very thin (less than $8 \mathrm{~nm}$ on the cpTi and Ti alloy plates studied). This may indicate that the layer was due to the transfer and adsorption of these elements from the tissue fluids, rather than a true apatite formation. In a similar investigation, $\mathrm{Li}$ and Ducheyne (63) showed that the $\mathrm{Ca}$ / $\mathrm{P}$ ratio formed was only 1.44 . This is lower than HA, as Ca was deficient on the surface oxide. They termed the layer a quasi-biological apatite, formed as phosphate ions bind to the Ti hyditoxide layer on the surface of cpTi in contact with aqueous solution. It is not known whether the intimate bone-Ti implant contact found in the normal clinical situation is due to the effect of the Ca-P layer formed on the surface of the oxide layer, since at the time of implantation, this layer is not present on implant surfaces.

\section{Biomechanical factors}

There are numerous designs of implant systems currently available. However, as mentioned above, the original Brånemark implant system is the best documented and researched implant system in current 
use. The Brånemark implant system was based on a twostage surgical procedure followed by the construction of either a fixed or removable precision attached prosthesis. It is assumed that when an implant is osseointegrated, the titanium implant and bone may be regarded as having a perfect fit, similar to the ankylosis of teeth in bone, with no stress in either material prior to loading.

However, flexibility in the Brånemark implant system may be found in the following:

1. gold cylinder and abutment which are fastened to the fixture by gold alloy and abutment screws, and

2. the connection between the superstructure and the abutments, which has been assumed to have perfect fit, by following an arbitrary designation of fit $(64,65)$.

An accurately fitting casting where the rigid prosthesis fits passively to all implants is essential to ensure that occlusal loads istributed to all fixtures, and unacceptable torquing stresses which may lead to loosening or fracturing of components, bone resorption and implant failure will be avoided. This is because the osseointegrated implants do not move in bone as teeth do, and therefore may not be able to compensate for a possible imperfect adaptation between the teeth and abutments (66). Nevertheless, it is generally believed that it is impossible to achieve a totally passive fit of a superstructure to more than one implant.

Presently we do not know the loads that individual implant units are subjected to when a superstructure is fixed and loaded. Brunski (67) pointed out that loads on a superstructure are not in general equal to loads on an implant. Several implants may be used to support a. prosthesis in vivo, and this problem of load sharing or load partitioning among implants has not been completely solved. He also stated that detailed understanding is lacking of the consequences of screwfastening misfitting prostheses to integrated implants.

Theoretically, passive adaptation involves the exact placement of a series of premachined parts in a casting to a strictly tolerated metal-metal interface. Practically this may be difficult to accomplish within the limits of presently available casting materials and techniques. This is due to the cumulative clinical and laboratory variables that are involved in making the casting (68).

It is also difficult to evaluate the passivity of fit of the castings in the clinical situation. Clinicians have been using the arbitrary term 'acceptable fit' in accepting castings clinically. Clinical evaluation of fit has been subjective and usually been desribed in the literature in terms of visual and tactile methods (69). Generally a casting is assessed to have acceptable fit by carefully seating the casting on one of the abutments, and visually checking the contact of the other gold cylinders on their respective abutments. One of the terminal abutments is then tightened, and a poor fit is revealed as a gap between the framework and an abutment. This gap might be a vertical gap, or a horizontal gap (skewed contact), with one side more open than the other. The rest of the other screws are then located one at a time, and contact between the casting and abutment assessed each time.

Distortion is inevitable in one-piece castings for multiple unit fixed bridges, and several authors have described techniques to overcome these problems $(65,70,71,72,73)$. However, even with careful soldering techniques, a discrepancy in fit of less than $30 \mathrm{~mm}$ in over $90 \%$ of prosthesis-abutment interface was described in one study (68). This means that single piece cast frameworks that appear to fit accurately by following an arbitrary designation of fit, will be seated through multiple screw-retained anchorage points by bending a casting to place during the tightening procedure, or by deforming the surfaces in contact (70). This was shown by Millington and Leung (74) who demonstrated in vitro using photoelastic stress analysis, stresses on the surface of the superstructure with gaps as small as $6 \mathrm{~mm}$ between the superstructure and abutments.

The Nobelpharma implant is a complicated multicomponent device joined by two screws, the abutment screw and the gold screw. When a screw is tightenend, a tensile force (preload) is built up in the stem of the screw $(75,76)$. This preload creates a compressive force to the components being clamped together, (in this case the abutment to the fixture, and the gold cylinder/ superstructure to the abutment). Assuming that there is perfect fit between the implants and all the gold cylinders in the superstructure, this compressive force is inevitable, as this will always be inherent in all screw joints, and the abutments will never be stress free. However it is the tensile stresses, or stresses that would tend to separate the components that would be more significant clinically. These stresses would undoubtedly be present in a situation where there would be variations in the degree of fit of contacting surfaces between the implants and the superstructure.

In vivo strain gauge measurements directly attached to the transmucosal abutment of a Branemark implant (24) and the intramobile element of the IMZ system (77) showed that the stress loading of the implant begins with fixation of the superstructure, even before any masticatory function occurrred. This implies that even though the connected implants had an acceptable fit, it may not be a completely passive fit and the cast framework that appears to fit can be torqued into position during the seating procedure. This would mean that a significant force may be introduced as the prosthesis is secured to the abutments. On the basis of these findings, a poor fit of the superstructure could introduce large stresses in the system and the bone around the implants $(78,79)$. This has been shown to be one common cause of fracture of abutment screws (80).

Another point to consider is the flexure of the mandible itself. It is conceivable that with varied openings of the mandible, the precise angulations of the fixtures and hence the transfer copings may change. The phenomenon of mandibular distortion in function has 
received little attention (81). Mandibular distortion will result in changes in the relationships of the dental arch across the midline, and is thus of considerable relevance in implant treatment because of the rigid fixation of the devices employed, and its deformation during impression making may result in inaccurately fitting frameworks.

Even though it has been agreed that complications can occur when a passive fit is not obtained, there is no data available to quantify what degree of imperfect fit is acceptable without leading to complications. This information is crucial for the following reasons:

1. It is impossible to achieve perfect fit of casting to abutments

2. Although osseointegrated implants are described as being immobile, the surrounding bone is viscoelastic, and it is likely that some degree of stress is induced as a result of accommodating to non-passive fit of the superstructure. This is probably one of the reasons for the high levels of long term success achieved by the Brånemark implant.

Obviously it is useful to quantify the degree of fit required of the cast superstructure in order to prevent complications as a result of stress induced from a nonpassive fit. However, until a more objective method of measuring the fit of superstructures is established, the acceptance or rejection of the fit of an osseointegrated prosthesis will ultimately be based on the judgement of the clinician. Poor fit may cause failure of abutment screws, failure of gold screws and possible loss of integration between the bone and implant. Injudicious implant placement is another factor which could generate high stresses on the implant components and the surrounding bone.

When a superstructure and final restoration are built upon an implant, the whole structure is based on both biological tissue and mechanical components. Rangert et al. (82) analysed data obtained from authors who reported failures in the literature due to fractured implants, and concluded that the fractures were caused by excessive bending overload on the implants. These excessive bending moments were basically a combination of different adverse loading conditions due to poor bone support, long cantilevers and broad buccolingual width of the teeth. Failures due to fractured implants may be prevented if these potential overload situations were identified before treatment (83).

The connection of the natural dentition to implants via a rigid attachment posed a theoretical concern that it may be hazardous to both implant and natural tooth survival (2). It is hypothesised that failure of either or both components might be due to the differences in the mobility of teeth and the deformation of the bone supporting the implant. Long-term studies had shown however, that there were no changes in implant or tooth failure rates where prostheses were supported by implants and natural teeth via a rigid connection $(84,85)$.
This suggests that the tooth and bone-implant components were able to undergo some deformation under functional load to compensate for the differences in their resiliency.

\section{Biologic factors}

The patient's medical status, type and quality of bone at the implant site, minimising tissue trauma at the time of surgery, prevention of infection, and good postoperative care are critical factors in the formation and maintenance of osseointegration $(19,86)$. Another factor which can affect the prognosis of oral implant treatment is smoking. Nicotine and other toxic materials absorbed into the blood stream through smoking have been proposed to cause adverse local and systemic effects which can affect the survival of the natural teeth (87). Local effects which have been proposed are altered salivary flow and microbial growth, while some systemic effects which have been associated with smoking are vasoconstriction, impaired wound healing after surgical treatment, and increased prevalence of bone loss.

Bain and Moy (88) and Lindquist et al. (89) showed that smoking may be directly related to the soft tissue changes and marginal bone loss around dental implants. As such, it should be considered a risk factor in implant therapy, separated from the other factors mentioned in a review article by Meffert et al. (28), which are primarily related to the maintenance of the implant in general.

\section{CONCLUSION}

Dental implants provide wider treatment options for replacing missing teeth, and most implant systems depend on an osseointegrated interface to achieve this. The results depend upon careful case selection, and good teamwork, and above all proper training and understanding of the clinical and biomechanical aspects of dental implants for all engaged in this form of treatment. However, with or without implants, an appropriate diagnosis and treatment plan must be formulated to address the patient's wishes and best interests, as the vast majority of partially and totally edentulous patients will receive functional and aesthetic prosthodontic care using the remaining teeth and mucosa without implant placement.

\section{REFERENCES}

1. Brånemark PI. Osseointegration and its experimental background. J Prosthet Dent 1983; 50: $399-410$.

2. Sullivan DY. Prosthetic considerations for the utilization of osseointegrated fixtures in the partially edentulous arch. Int $\mathbf{J}$ Oral Maxillofac Implants 1986; 1: 39-45. 
3. Wyatt CCL, Zarb GA. Treatment outcomes of patients with implant-supported fixed partial prostheses. Int J Oral Maxillofac Implants 1998; 13: 204-211.

4. Parel SM, Holt R, Brånemark PI, Tjellstrõm A. Osseointegration and facial prosthetics. Int $\mathrm{J}$ Oral Maxillofac Implants 1986; 1: 27-29.

5. Bergendal B, Bergendal T, Hallonsten AL, Koch G, Kurol J, Kvint S. A multidisciplinary approach to oral rehabilitation with osseointegrated implants in children and adolescents with multiple aplasia. Euro J Orthod 1996; 18: 119-129.

6. Becker W, Becker BE, Israelson H, Lucchini JP, Handelsman M, Ammons W, Rosenberg E, Rose L, Tucker LM, Lekholm U. One-step surgical placement of Brånemark implants: A prospective multicentre clinical study. Int $\mathrm{J}$ Oral Maxillofac Implants 1997; 12: 454-462.

7. Buser D, Belser UC, Lang NP. The original onestage dental implant system and its clinical application. Periodontology 2000 1998; 17: 106118.

8. Jisander S, Grenthe B, Alberius P. Dental implant survival in the irradiated jaw: A preliminary report. Int J Oral Maxillofac Implants 1997; 12: 643-648.

9. Keller EE. Placement of dental implants in the irradiated mandible: A protocol without adjunctive hyperbaric oxygen. J Oral Maxillofac Surg 1997; 55: 972-980.

10. Niimi A, Ueda M, Keller EE, Worthington P. Experience with osseointegrated implants placed in irradiated tissues in Japan and the United States. Int J Oral Maxillofac Implants 1998; 13: 407-411.

11. Nishimura RD, Roumanas E, Beumer J, Moy PK, Shimizu KT. Restoration of irradiated patients using osseointegrated implants: Current perspectives. J Prosthet Dent 1998; 79: 641-647.

12. Brånemark PI. Osseointegration: Biotechnological perspective and clinical modality. In: Brånemark PI, Rydevik BL, Skalak R, eds. Osseointegration in skeletal reconstruction and joint replacement. Quintessence Publishing Co. Inc., Chicago 1994; $1-24$.

13. Brånemark PI. Introduction to osseointegration. In: Brånemark PI, Zarb GA, Albrektsson T, eds. Tissue-integrated prostheses. Quintessence Publishing Co. Inc., Chicago. 1985; 11-76.

14. Albrektsson T, Johansson C. Quantified bone tissue reactions to various metallic materials with reference to the so-called osseointegration concept.
In: Davies JE, ed. The bone-biomaterial interface. University of Toronto Press, Toronto 1991; 357363.

15. Steflik DE, Corpe RS, Lake FT, Sisk AL, Parr GR, Hanes PJ, Buttle K. Composite morphology of the bone and associated support-tissue interfaces to osseointegrated dental implants: TEM and HVEM analyses. Int J Oral Maxillofac Implants 1997; 12: 443-453.

16. Zarb GA, Albrektsson T. Osseointegration: A requiem for the periodontal ligament? Int J Periodontics Restorative Dent 1991; 11: 88-91.

17. Skalak R, Brånemark PI. Definition of osseointegration. In: Brånemark PI, Rydevik BL, Skalak R, eds. Osseointegration in skeletal reconstruction and joint replacement. Quintessence Publishing Co. Inc., Chicago 1994; xi.

18. Cooper LF. Biologic determinants of bone formation for osseointegration: Clues for future clinical improvements. J Prosthet Dent 1998; 80: 439-449.

19. Albrektsson T, Zarb G, Worthington P, Eriksson AR. The long-term efficacy of currently used dental implants: A review and proposed criteria of success. Int J Oral Maxillofac Implants 1986; 1: 11-25.

20. Røynesdal A, Ambjørnsen E, Støvne S, Haanæs HR. A comparative clinical study of three different endosseous implants in edentulous mandibles. Int $\mathrm{J}$ Oral Maxillofac Implants 1998; 13: 500-505.

21. Esposito M, Hirsch JM, Lekholm U, Thomsen P. Biological factors contributing to failures of osseointegrated oral implants (I). Success criteria and epidemiology. Eur J Oral Sci 1998; 106: 527551.

22. Zarb GA, Albrektsson T. Consensus report Towards optimized treatment outcomes for dental implants. J Prosthet Dent 1998; 80: 641.

23. Albrektsson T, Sennerby L. State of the art in oral implants. J Clin Periodontol 1991; 18: 474-481.

24. Jemt, T. Failures and complications in 391 consecutively inserted fixed prostheses supported by Brånemark implants in edentulous jaws: A study of treatment from the time of prosthesis placement to the first annual checkup. Int J Oral Maxillofac Implants 1991; 6: 270-275.

25. Esposito M, Hirsch JM, Lekholm U, Thomsen P Biological factors contributing to failures of osseointegrated oral implants (II). Etiopathogenesis. Eur J Oral Sci 1998; 106: 721-764. 
26. Szmukler-Moncler S, Salama H, Reingewirtz Y, Dubruille JH. Timing of loading and effect of micromotion on bone-dental implant interface: Review of experimental literature. J Biomed Mater Res 1998; 43: 192-203.

27. Legeros RZ, Craig RG. Strategies to affect bone remodelling: Osteointegration. I Bone Miner Res 1993; 8: S583-S596.

28. Meffert RM, Langer B, Fritz ME. Dental implants: A review. J Periodontol 1992; 63: 859-870.

29. Glantz PO. Biomaterial considerations for the optimised therapy for the edentulous predicament. J Prosthet Dent 1998; 79: 90-92.

30. Hench LL, Wilson J. Introduction. In: Hench LL, Wilson, eds. An introduction to bioceramics Advanced Series in Ceramics, vol. 1. World Scientific, Singapore 1993: 1-24.

31. Glantz PO. The choice of alloplastic materials for oral implants: Does it really matter? Int J Prosthodont 1998; 11: 402-407.

32. Ellingsen JE. Surface configurations of dental implants. Periodontology 2000 1998; 17 36-46.

33. Pilliar RM, Deporter DA, Watson PA, Pharoah M, Chipman M, Valiquette N, Carter S, Degroot K. The effect of partial coating with hydroxyapatite on bone remodelling in relation to porous coated titanium alloy dental implants in the dog. J Dent Res 1991; 70: 1338-1345.

34. Hayashi K, Inadome T, Tsumura H, Nakashima Y, Sugioka Y. Effect of surface roughness of hydroxyapatite-coated titanium on the bone-implant interface shear strength. Biomaterials 1994; 15: 1187-1191.

35. Zablotsky MH. Hydroxyapatite coatings in implant dentistry (Review). Implant Dent 1992; 1: 253-257.

36. Wheeler SL. Eight-year clinical retrospective study of titanium plasma-sprayed and hydroxyapatitecoated cylinder implants. Int J Oral Maxillofac Implants 1996; 11: 340-350.

37. Ogiso M, Yamashita M, Matsumoto T. The process of physical weakening and dissolution of the HAcoated implant in bone and soft tissue. J Dent Res 1998; 77: 1426-1434.

38. Mah C. The evolution of implants over the last fifty years. Aust Prosthodont J 1990; 4: 47-52.

39. Brown D. All you wanted to know about titanium, but were afraid to ask. Br Dent J 1998; 182: 393394.
40. Wataha JC. Review: Materials for endosseous dental implants. J Oral Rehabil 1996; 23: 79-90.

41. Johansson $\mathrm{CB}$, Han $\mathrm{CH}$, Wennerberg A, Albrektsson T. A quantitative comparison of machined commercially pure titanium and titaniumaluminium-vanadium implants in rabbit bone. Int $\mathrm{J}$ Oral Maxillofac Implants 1998; 13: 315-321.

42. Lincks J, Boyan BD, Cochran DL, Liu Y, Blanchard C, Dean DD, Schwartz Z. MG63 cells discriminate between surface roughness and material composition. J Dent Res. 1998; 77 (Special issue A): 246, Abstr. 1123.

43. Legeros RZ, Orly I, Gregoire M, Daculsi G. Substrate surface dissolution and interfacial biological mineralization. In: Davies JE, ed. The bone-biomaterial interface. University of Toronto Press, Toronto 1991: 76-88.

44. Thompson G J, Puleo DA. Ti-6Al-4V ion solution inhibition of osteogenic cell phenotype as a function of differentiation timecourse in vitro. Biomaterials 1996; 17: 1949-1954.

45. Lautenschlager EP, Monaghan P. Titanium and titanium alloys as dental materials. (Review). Int Dent J 1993; 43: 245-253.

46. Kasemo B. Biocompatibility of titanium implants: Surface science aspects. J Prosthet Dent 1983; 49: 832-837.

47. Kasemo B, Lausmaa J. Biomaterial and implant surfaces: A surface science approach. Int J Oral Maxillofac Implants 1988; 3: 247-259.

48. Meenaghan MA, Natiella JR, Moresi JL, Flynn HE, Wirth JE, Baier RE. Tissue response to surfacetreated tantalum implants: Preliminary observations in primates. J Biomed Mater Res 1979; 13: 631643.

49. Swart KM, Keller JC, Wightman JP, Draughn RA, Stanford CM, Michaels CM. Short-term plasmacleaning treatments enhance in vitro osteoblast attachment to titanium. J Oral Implantol 1992; 18: 130-137.

50. Larsson C, Thomsen P, Lausmaa J, Rodahl, M, Kasemo B, Ericson LE. Bone response to surface modified titanium implants: Studies on electropolished implants with different oxide thicknesses and morphology. Biomaterials 1994; 15: 1062-1074.

51. Callen BW, Lowenberg BF, Lugowski S, Sodhi RNS, Davies JE. Nitric acid passivation of Ti6Al4V reduces thickness of surface oxide layer and 
increases trace element release. J Biomed Mater Res 1995; 29: 279-290.

52. Larsson C, Thomsen P, Aronsson BO, Rodahl M, Lausmaa J, Kasemo B, Ericson LE. Bone response to surface-modified titanium implants: Studies on the early tissue response to machined and electropolished implants with different oxide thicknesses. Biomaterials 1996; 17: 605-616.

53. Lugowski SJ, Smith DC, McHugh AD, Van Loon JC. Release of metal ions from dental implant materials in vivo: Determination of $\mathrm{Al}, \mathrm{Co}, \mathrm{Cr}, \mathrm{Mo}$, $\mathrm{Ni}, \mathrm{V}$, and $\mathrm{Ti}$ in organ tissue. $\mathrm{J}$ Biomed Mater Res 1991; 25: 1443-1458.

54. Healy KE, Ducheyne P. The mechanisms of passive dissolution of titanium in a model physiological environment. J Biomed Mater Res 1992; 26: 319338.

55. Smith DC, Lugowski S, McHugh A, Deporter D, Watson PA, Chipman M. Systemic metal ion levels in dental implant patients. Int J Oral Maxillofac Implants 1997; 12: 828-834.

56. Steinemann SG. Titanium - the material of choice? Periodontology 2000 1998; 17: 7-21.

57. Williams DF. Biocompatibility: An overview. In: Williams D, ed Concise encyclopaedia of medical and dental materials. Pergamon Press, Oxford 1990: 51-59.

58. Stanford CM, Keller JC. The concept of osseointegration and bone matrix expression. Crit Rev Oral Biol Med 1991; 2: 83-101.

59. Rahal MD, Brånemark PI, Osmond DG. Response of bone marrow to titanium implants: Osseointegration and the establishment of a bone marrow-titanium interface in mice. Int $\mathrm{J}$ Oral Maxillofac Implants 1993; 8: 573-579.

60. Sennerby L, Thomsen P, Ericson LE. Ultrastructure of the bone-titanium interface in rabbits. J Mater Sci Mater Med 1992; 3: 262-271.

61. Yliheikkilä PK, Felton DA, Whitson SW, Ambrose WW, Uoshima K, Cooper LF. Correlative microscopic investigation of the interface between titanium alloy and the osteoblast-osteoblast matrix using mineralizing cultures of primary foetal bovine mandibular osteoblasts. Int J Oral Maxillofac Implants 1995; 10: 655-665.

62. Hanawa T. Titanium and its oxide film: A substrate for formation of apatite. In: Davies JE, ed. The bone-biomaterial interface. University of Toronto Press, Toronto. 1991: 49-61.
63. Li P, Ducheyne P. Quasi-biological apatite film induced by titanium in a simulated body fluid. J Biomed Mater Res 1997; 41: 341-348.

64. Rangert B, Gunne J, Sullivan DY. Mechanical aspects of a Brånemark implant connected to a natural tooth: an in vitro study. Int $J$ Oral Maxillofac Implants 1991; 6: 177-186.

65. Wee AG, Aquilino SA, Schneider RL. Strategies to achieve fit in implant prosthodontics: a review of the literature. Int J Prosthodont 1999; 12: $167-$ 178.

66. Adell R. Tissue integrated prosthesis in clinical dentistry. Int Dent J 1985; 35: 259-265.

67. Brunski JB. Biomechanical factors affecting the bone-dental implant interface. Clin Mater 1991; 10: 153-201.

68. Klineberg IJ, Murray GM. Design of superstructures for osseointegrated fixtures. Swed Dent J 1985; 28(Suppl): 63-69.

69. Kan JYK, Rungcharassaeng K, Bohsali K, Goodacre CJ, Lang BR. Clinical methods for evaluating implant framework fit. J Prosthet Dent 1999; 81: $7-13$

70. Parel SM. Modified casting technique for osseointegrated fixed prosthesis fabrication: a preliminary report. Int J Oral Maxillofac Implants 1989; 4: 33-40.

71. Zarb G, Schmitt A. The longitudinal clinical effectiveness of osseointegrated dental implants: The Toronto study. Part II: the prosthetic results. J Prosthet Dent 1990; 64: 53-61.

72. Sellers GC. Direct assembly framework for osseointegrated implant prosthesis. J Prosthet Dent 1989; 62: 662-668.

73. McCartney JW, Doud R. Passive adaptation of the prosthesis-implant interface by soldering gold cylinders to the framework casting. J Prosthet Dent 1993; 70: 17-20.

74. Millington ND, Leung T. Stress on an implant superstructure in relation to its accuracy of fit. J Dent Res (Abstract no:108) 1992; 71: 529.

75. Jorneus L, Jemt T, Carlsson L. Loads and designs of screw joints for single crowns supported by osseointegrated implants. Int J Oral Maxillofac Implants 1992; 7: 353-359.

76. McGlumphy EA, Mendel DA, Holloway JA. Implant screw mechanics. Dent Clin North Am 1998; 42: 71-89. 
77. Setz J, Kramer A, Benzing U, Weber H. Complete dentures fixed on dental implants: chewing patterns and implant stress. Int J Oral Maxillofac Implants 1989; 4: 107-111.

78. Isa ZM, Hobkirk JA. The effects of superstructure fit and loading on individual implant units: Part I. The effects of tightening the gold screws and placement of a superstructure with varying degrees of fit. Eur J Prosthodont Restor Dent 1995; 3: 247 253.

79. Isa ZM, Hobkirk JA. The effects of superstructure fit and loading on individual implant units: Part 2. The effects of loading a superstructure with varying degrees of fit. Eur J Prosthodont Restor Dent 1996; 4: 11-14.

80. Lekholm U, Adell R, Brånemark PI. Complications. In: Brånemark PI, Zarb GA, Albrektsson T, eds. Tissue-integrated prostheses. Quintessence Publishing Co. Inc., Chicago. 1985; 233-240.

81. Hobkirk JA, Schwab J. Mandibular deformation in subjects with osseointegrated implants. Int J Oral Maxillofac Implants 1991; 6: 319-328.

82. Rangert B, Krogh PHJ, Langer B, Van Roekel N. Bending overload and implant fracture: A retrospective clinical analysis. Int J Oral Maxillofac Implants 1995; 10: 326-334.
83. Rangert BR, Sullivan RM, Jemt T. Load factor control for implants in the posterior partially edentulous patients. Int J Oral Maxillofac Implants 1997; 12: 360-370.

84. Van Steenberghe D. A retrospective multicentre evaluation of the survival rate of osseointegrated fixtures supporting fixed partial prostheses in the treatment of partial edentulism. J Prosthet Dent 1989; 61: 217-223.

85. Naert I, Quirynen M, Van Steenberghe D, Darius P. A six-year prosthodontic study of 509 consecutively inserted implants for the treatment of partial edentulism. J Prosthet Dent 1992; 67: 236245.

86. Weyant, RJ. Characteristics associated with the loss and peri-implant tissue health of endosseous dental implants. Int J Oral Maxillofac Implants 1994; 9: 95-102.

87. Krall EA, Dawson-Hughes B, Garvey AJ, Garcia RI. Smoking, smoking cessation, and tooth loss. J Dent Res 1997; 76: 1653-1659.

88. Bain CA, Moy PK. The association between the failure of dental implants and cigarette smoking. Int J Oral Maxillofac Implants 1993; 8: 609-615.

89. Lindquist LW, Carlsson GE, Jemt T. Association between marginal bone loss around osseointegrated mandibular implants and smoking habits: A 10-year follow-up study. J Dent Res 1997; 76: 1667-1674. 